\title{
ФОЛЬКЛОРИСТИКА
}

\section{Мотивы космогонического мифа о небесном охотнике и трех маралах в фольклоре калмыков}

\section{Данара Владимировна Убушиева ${ }^{1}$}

\author{
${ }^{1}$ Калмыцкий научный центр РАН (д. 8, ул. им. И. К. Илишкина, 358000 Элиста, \\ Российская Федерация) \\ кандидат филологических наук, старший научный сотрудник \\ iD 0000-0002-5547-4006. E-mail: bib.danara@yandex.ru
}

\author{
(C) КалмНЦ РАН, 2021 \\ (С) Убушиева Д. В., 2021
}

\begin{abstract}
Аннотация. Введение. Калмыцкий фольклор содержит множество «узнаваемых» мотивов и сюжетов, восходящих к мифологии. Одним из таких архаических сюжетов является универсальный для тюрко-монгольских народов космогонический миф о небесном охотнике и трех маралах. Цель статьи - реконструировать космогонический миф о небесном охотнике и трех маралах в калмыцком эпическом фонде. Актуальным является его реконструкция через типологические сопоставления, поскольку этот миф легко «узнаваем» в различных традициях. Материалом исследования послужили тексты песен раннего Багацохуровского цикла калмыцкого героического эпоса «Джангар». В работе применены структурно-семантический, структурно-типологический и сопоставительный методbl. В результате проведенного исследования были сделаны следующие вblвoдbl. Структурно-семантический анализ мотива выявил его архаические корни, восходящие к представлениям о космогоническом начале. Эпический сюжет о двигающемся по лунной дороге богатыре Саваре, охотящемся на оленей и маралов, восходит к космогоническому мифу о небесном стрелке (Сириус) и трех маралах (звезды из пояса созвездия Орион). Более того, в образе богатыря Савара, возможно, прослеживаются элементы, восходящие к архаическому мифу о медведе-охотнике, преследующем оленей, укравших солнце. Результаты проведенного исследования подтверждают мнение исследователей о том, что в архаичном календаре предков калмыков основными символами являлись образы копытного животного и медведя, и о том, что образ небесного стрелка в древнейшем мифе ряда народов о первотворении сменил мифологический облик медведя, освобождающего солнце.
\end{abstract}

Ключевые слова: космогонический миф, эпос «Джангар», богатырь Савар, Сириус, три маралухи, медведь

Благодарность. Исследование проведено в рамках государственной субсидии проект «Устное и письменное наследие монгольских народов России, Монголии и Китая: трансграничные традиции и взаимодействия〉 (номер госрегистрации: АAАAA19-119011490036-1).

Для цитирования: Убушиева Д. В. Мотивы космогонического мифа о небесном охотнике и трех маралах в фольклоре калмыков // Монголоведение. 2021. Т. 13. № 3. C. 567-576. DOI: $10.22162 / 2500-1523-2021-3-567-576$ 


\title{
Cosmogonic Myth of Heavenly Hunter (Sirius) and Three Marals (Orion's Belt): The Motifs in Kalmyk Folklore Revisited
}

\section{Danara V. Ubushieva ${ }^{1}$}

\author{
${ }^{1}$ Kalmyk Scientific Center of the RAS (8, Ilishkin St., 358000 Elista, Russian Federation) \\ Cand. Sc. (Philology), Senior Research Associate \\ iD 0000-0002-5547-4006. E-mail: bib.danara@yandex.ru
}

\author{
(C) KalmSC RAS, 2021 \\ (C) Ubushieva D. V., 2021
}

\begin{abstract}
Introduction. There are a great number of "familiar" motifs and plotlines in Kalmyk folklore that originate from mythology. One such archaic story of a universal character in the Turkic-Mongolian world is a cosmogonic myth of the heavenly hunter and the three red deer. The article aims to attempt at reconstructing this cosmogonic myth in the Kalmyk epic heritage. Importantly, such reconstruction requires typological comparisons because the story is easily "identified" in a variety of traditions. The research materials used are the texts of early Baga Tsokhur cycle sagas of Kalmyk heroic epic "Djanggar". The analysis was based on structural-semantic, structural-typological, and comparative methods. As a result, the author comes to the following conclusions. The structural-semantic analysis of the motif manifests its archaic roots originating from the ideas of cosmogonic beginnings of the universe. The epic story relating of Savar Warrior following the moon path while hunting deer and red deer originates from a cosmogonic myth of the heavenly marksman [Sirius] and the three red deer [the stars from the belt of the constellation Orion]. Moreover, the character of Savar Warrior shows some elements that may be associated with the archaic myth of a bear-hunter chasing the deer that stole the sun. The results of the present study agree with other researchers' views, according to which, the principal symbols that the archaic calendar of the Kalmyk ancestors included were the images of a hoofed animal and a bear and that the image of the heavenly hunter of the ancient myth relating of the world beginning characteristic of a number of folklore traditions was a substitute of the mythological bear, the liberator of the sun.
\end{abstract}

Keywords: cosmogonic myth, epic "Djanggar", Savar Warrior, Sirius, three red deer, bear Acknowledgement. The reported study was funded by government subsidy, project no. AAAA-A19-119011490036-1 'Oral and Written Heritage of Mongolic Peoples of Russia, Mongolia and China: Cross-Border Traditions and Interactions'.

For citation: Ubushieva D. V. Cosmogonic Myth of Heavenly Hunter (Sirius) and Three Marals (Orion's Belt): The Motifs in Kalmyk Folklore Revisited. Mongolian Studies (Elista). 2021; 13 (3): 567-576. (In Russ.). DOI: 10.22162/2500-1523-2021-3-567-576

\section{Введение}

В калмыцкой астральной мифологии отражены общие для тюрко-монгольских народов представления и знания о небесных объектах. Калмыками почитались Солнце, Луна и звезды. В народном знании калмыков сохранились представления о созвездиях Долан бурхн ('Большая Медведица'), Мөчд ('Плеяды'), о звезде Алтн һасн ('Полярная звезда') и др. [Омакаева 1993; Бакаева 2009; Бакаева 2010; Бакаева 2020а; Бакаева 2020б; и др.].

В настоящей статье рассматриваются мотивы космогонического мифа о небесном охотнике, который превращается в самую яркую звезду (т. е. Сириус) и трех маралах (которые превращаются в звезды пояса Ориона) в фольклоре калмыков. Сказочно-эпическая традиция содержит мотивы о них в имплицитном 
виде; при соотнесении с элементами календарной традиции калмыков и типологическими параллелями с тюрко-монгольскими архаическими представлениями эти мотивы становятся явными.

\section{Архаические обрядовые праздники}

Представления космогонического характера проявляются в календарной обрядности народов и выражаются в праздниках.

Известно, что для якутов день летнего солнцестояния является архаическим обрядовым праздником, посвященным Солнцу, плодородию и коневодству. Е. Н. Романова обращает внимание на то, что «Г. В. Ксенофонтов определял Ысыах как праздник торжественной встречи восхода летнего солнца. А. И. Гоголев, развив положение ученого, рассматривает Ысыах как „культовый праздник плодородия, справляемый в начале года, соединяющий воедино элементы обожествления солнца, неба и земли“» [Романова 2012: 250].

У бурят накануне дня летнего солнцестояния - в июне - проводился обряд, посвященный божеству Ухаа Солбон. Н. Б. Дашиева отмечает, что «с этого времени в хозяйстве скотоводов с табунным разведением коней начинался сезон дойки кобылиц, который заканчивался в сентябре. Местом проведения обряда являлся загон для лошадей. Здесь устанавливали девять берез делбэргэ и вокруг изгороди втыкали березовые ветки туургэ. Божеству Ухаa Солбон возносили девятикратное кропление кумыса из девяти котлов и посвящали жеребца-производителя соловой масти...» [Дашиева 2004: 224].

В XIX-XX вв. разными российскими исследователями среди калмыков также были зафиксированы летние праздники, близкие дню солнцестояния. И. И. Лепехин записывает, что «...годовых праздников считают они три: первый называется Сага сара, второй Зула, а третий Цаган сара. Сага сара празднуется у них с начала мая месяца, и с сего праздника почитается у них новый год» [Лепехин 1771: 476]. П. С. Паллас также наблюдает этот праздник: «... в июне по восхождении нового месяца бывает небольшой праздник, который они сага-сара и сюни-түрүн-сара (начало лета) называют» [Паллас 1773: 525]. Э. П. Бакаева приводит описание праздника Yp сар со ссылкой на А. М. Позднеева [Бакаева 2009: 42], которое аналогично описанию этого же праздника, данного И. И. Поповым:

Когда домашние животные уже благополучно вылли, по подлинному выражению калмыков, «из ужасов зимнего времени» и, вполне оправивщись, стали давать наибольшее количество молока, наступает по калмыцкому календарю первыйлетний месяи овиы (хонинь-сара), иначе «ӥгӥсъ». Молоко - главная пища калмыков; из него же приготовляется увеселяющая сердие водка (хара-арки). Полным контрастом после голодной зимы является сытый, богатый «ӥгӥсъ», а потому с издревле и по сие время торжественно и весело празднуется его наступление в донской калмыцкой степи. Зеленью, подобно тому, как у нас в Троицьн день, украшаются храмы и обтянутые бельми полстями подвижные дома-кибитки (гэрмӥдъ). Ранним утром, еще до восхода солнца, вырезаются в этот день куски дерна, в котором должна находиться трава «суль бӧксо», т. е. железняк, называемая также в честь этого празднества «ӥрӥсъ ӧвӧсӧнъ». Такой дерн приносят в кибитку и устраивают его перед бараном ${ }^{1}$. Пучок нарезанного с его лиловенькими цветочками железняка заты-

${ }^{1}$ «Место у стены против двери, где находятся завешанные коврами сундуки. Это место считается лучшим и даже отчасти священным, так как здесь бывают также изображения божеств и духовные книги. Здесь же возжигаются лампады и поставляются в жертву начатки кушаний» (прим. И. И. Попова [Попов 1919: 284-286]). 
кают за униньг ${ }^{2}$ против «барана» или полагают поверх его самого. Другие вырезки дерна кладут около «зэль»³. Лишь только начинает всходить солнце, старший по летам член семьи (мужчина или женщина) становится перед бараном и произносит какую-либо, знакомую ему, краткую молитву.

Здесь же он наливает в чашку «чигэнъ» ${ }^{4}$, куда подбавляет также немного водки.

В эту чашку в виде кропила опускается помянутый раньше, положенный на «баранъ» пучок железняка. Все находящееся в кибитке семейство выходит наружу.

Здесь стариий семьи читает, обращаясь к восходящему солниу, особую молитву. Во время ее произнесения или после него совершается сначала кропление всех четьрех сторон света белого, а затем окропляются головы присутствующих детей.

Подходят к привязанным молодым животным и, произнося мистически священные слова: «омъ-ма-хомъ-иӧкъ», окропляют также и их. В молитве благоговейно воздаются поклонения лазурной небесной атмосфере, светилам: Солниу и Луне, центру вселенной - высящейся среди великого внешнего океана-моря горе Сӥмэру. Возносятся моления главе желтошапочных буддистов, к которым принадлежат по религии и наши донские калмыки, Далай-ламе и всему соборному сонму духовенства. Вспоминаются места последних, перед приходом в Россию, кочевий: снежная гора Алтай, шумливый, бурный Иртыши-река [Попов 1919: 284-286].

Неизменным во всех традициях остается посвящение праздника Солнцу, плодородию и «новому году» по двоичной структуре годового цикла и проведение в день летнего солнцестояния либо - у калмыков - в 15 день первого летнего месяца по лунно-солнечному календарю (т. е. близко ко дню летнего солнцестояния). Имеются и детальные схождения - это встреча первых лучей Солнца; подношение белой пищи старшим; коновязные столбы сэргэ у якутов и столбы зэлэ для привязи телят, жеребят у калмыков; березовые ветки, прикрепляемые к главным столбам Могол ураса ${ }^{5}$ и пучок зеленой травы железняка, который помещали между решетками юрты; Могол ураса и юрта являются сакральными пространствами; отсчет «нового года» по сезонному календарю, символизирующего новое рождение, плодородие.

Весьма примечательно, что типологически и семантически архаический калмыцкий праздник середины первого летнего месяца по лунно-солнечному календарю близок обрядам бурятских коневодов и якутскому празднику Ысыах.

По мнению Н. Б. Дашиевой, переход от охотничьего хозяйствования к скотоводческому привел к замене мифологемы «звезда-олень» на мифологему «звезда-конь» [Дашиева 2001: 69].

Цель настоящей статьи - реконструкция в фольклоре калмыков мифологемы «звезда-олень», восходящей к архаическому мифу об охоте богатыря (или животного) на копытных, выкравших Солнце, являющегося основным календарным мифом ряда народов Центральной Азии и Сибири.

2 «Тонкие шесты, образующие вроде стропил остов крыши кибитки и входящие в «харачи», круг дымового отверстия» (прим. И. И. Попова [Попов 1919: 284-286]).

${ }^{3}$ «Привязь для молодых животных: телят, жеребят, ягнят и козлят, если матери их доятся» (прим. И. И. Попова [Попов 1919: 284-286]).

${ }^{4}$ «Кумыс или арьян - особого рода кислое молоко» (прим. И. И. Попова [Попов 1919: 284-286]).

${ }^{5}$ Могол ураса - коническое стационарное сооружение, покрытое берестяными полотнищами, представляет собой летний тип жилища [Данилова 2016: 135]. 


\section{Космогонический миф о небесном охотнике}

В традиционной культуре народа саха и в настоящее время главным праздником является Ысыах, проводимый в день летнего солнцестояния.

Н. Б. Дашиевой в структуре народного календаря бурят выделен прообраз солнечного календаря, основанный на циклах обращения созвездия Орион и Сириуса [Дашиева 2001].

Этнографические материалы по калмыкам также свидетельствуют об использовании калмыками, а ранее ойратами солнечного календаря. Э. П. Бакаева подчеркивает, что «...в современной традиции калмыков сохранились как праздники, привнесенные в XVII в. с широким распространением буддизма, так и древнейшие праздники их предков — ойратов: Жилин эзн (22 декабря) и $Y p c$ cap $<\ldots>$, которые в различные периоды считались также и началом отсчета года» [Бакаева 2010: 290].

В бурятской мифологии небесным охотником является Хухэдэй Мэргэн, который наделен функциями «божественного предка, творца и громовника, который в течение холодного периода года гонится за небесными маралами (звезды пояса Орион)» [Дашиева 2001: 85]. К тому же день солнцестояния у бурят связан с периодом обращений созвездия Орион и Сириуса [Дашиева 2004: 225].

Э. П. Бакаева также отмечает, что «в мифологических сказаниях монголов и ойратов образ Хухэдэй Мэргэна связан с представлением о созвездии Орион, но в текстах упоминается и Большая Медведица. Так, считается, что три маралухи, которых преследовал Хухэдэй Мэргэн, превратились в три звезды Пояса Ориона. Сам же Хухэдэй Мэргэн — в самую яркую звезду на зимнем небе, т. е. Сириус, находящийся на одной линии от Пояса Ориона ближе к горизонту что символизирует следование охотника за маралами» [Бакаева 2020б: 670].

На наш взгляд, в сюжете эпической песни «О Замбал хане» раннего Багацохуровского цикла калмыцкого героического эпоса «Джангар» эпизод охоты богатыря Савара на оленей и маралов также восходит к сюжету о космическом стрелке.

Предваряя данную охоту, богатырь Савар выезжает из дворца Джангара и объезжает дворец против солнца:

І песнь Багацохуровского цикла (далее - Б. Ц.) — [15] $\left(23^{6}\right)$ šara (24) cōxor bumbalbaiyigiyni burū ergēd (25) odbi: 'Жёлто-пёстрый дворец его неправильно объехав, отправился ${ }^{8}$ [НА РГО. Оп. 1. Р. 53. Д. 15. Л. 15].

Это не характерно как для эпического текста, так и в целом для традиции калмыков, так как в культуре монголоязычных народов движения совершаются посолонь. Но если рассматривать богатыря Савара как возможного космического охотника, то можно считать, что это первая предпосылка к мифу, где движение происходит с запада на восток в соответствии с лунной траекторией, тем более за выездом следует сюжет охоты на оленей и маралов.

Так, Н. Б. Дашиева указывает, что «...в графическом осмыслении движение в течение ночи - в суточном цикле и в течение зимне-весеннего сезона — в го-

6 Здесь и далее в транслитерации первая цифра в квадратных скобках обозначает страницы рукописи, вторая цифра, помещенная в круглые скобки, обозначает номер строки на странице.

${ }^{7}$ Т. е. не по направлению движения солнца.

8 Здесь и далее перевод Д. В. Убушиевой. 
довом цикле, представляется в виде вектора с направлением „запад-восток“ (против хода Солнца), а временной с вечера до утра. Это период мифологического творения Солнца» [Дашиева 2004: 226].

Движение против хода солнца отмечается и в празднике Ысыах, Е. Н. Романова пишет, что «...в начале хоровода все три круга совершали движение по ходу Солнца вокруг центрального столба. Затем они уходили с площади тюсюлгэ через восточный „солнечный“ проход и трижды кружились вокруг восточной коновязи аap багах, называемой еще айыlы сэргэтэ в обратном направлении, т. е. лунной дорогой» [Романова 2012: 222].

Выехав из ставки в соответствии с лунной траекторией, богатырь Савар въезжает на гору и всматривается в чащу леса у подножия этой горы, там он видит пасущихся оленей и маралов и выбирает своей целью оленя, цветом подобного звезде:

І песнь Б. Ц. — [15об.] erkü- (6) lügiyin mönggön caүān ūlain oroi (7) dēreni yarād: dörbön ǰilei širtēd (8) ügei dönön xara bürgüdiyin nider šir- (9) tēd: dörbön tibiyin oroiyigi doqdol- (10) tuluni xalēbi: öi dunduni xalexuni (11) buya maral xoyor üzüqdebe: kökö (12) debēn öbösön: kiyitin buluq usun: (13) kür zandan modon südürtei genei-la: < . >> (26) sayixan kürünggiyin amiyni ergülēd 16 (1) xōrōn tatabi: öndör cayān ūlayin (2) urū kömörü ödöni orōd: öiygiyin (3) olon buya marlāsa odon adli önggö- (4) tēgii-ni: erbelzeqsen kürünggēren (5) ēreǰi baiǰi erken tarayaniyini

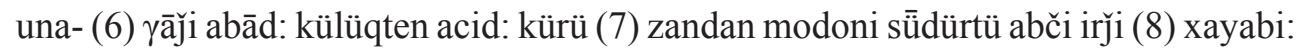
'Взобравшись на вершину белой серебряной горы Эркюлю, стал всматриваться глазами четырехлетнего беркута, что четыре года не смотрел. Так смотрел, что сотрясались все четыре материка. Посмотрел в середину леса и увидел оленей и маралов. У зеленой травы, у прохладной родниковой воды, в тени кругом [растущих] сандаловых деревьев, говорят. < .. > Развернув свою красивую Кюрюнг, потянул в сторону. Пустился вниз к подножию высокой белой горы. Из множества лесных оленей и маралов [выбрал] тех, что цветом подобны звездам. На парящей своей Кюрюнг, окружая их, в самую упитанную [выстрелив], уронил. Погрузил на скакуна. Привез и бросил в тени кругом [растущих] сандаловых деревьев' [НА РГО. ОП. 1. Р. 53. Д. 15. Л. 15об.-16].

На наш взгляд, этот эпизод охоты Савара на оленей и маралов, возможно, и есть рудимент мифа о космическом стрелке, в имплицитном виде сохранившийся в эпическом сюжете. Возможно, образ Савара-охотника на оленей и маралов восходит к самой ранней трактовке мифа, где охотником за оленями является медведь. Именно богатыря Савара ассоциируют с медведем.

Так, боевое оружие Савара балт ('боевой топор, секира') называется әәв балт, что возводят к тюрк. ай балта 'луна-топор' [Бакаева 2003: 88]. В ойратском словаре, составленном на основе текстов «Джангара» Б. Х. Тодаевой, читаем: «балта (балту) топор; әә-балта, сара-балта парн. боевой топор, топор, секира...» [Тодаева 2001: 54], - таким образом, слова әә и сара используются как взаимозаменяемые. Имя Савар ученые возводят к монг. сава 'бить, ударять, выбивать' [Пюрбеев 2015: 28] и савар/савр 'звериная лапа' [Кичиков 1980: 431; Бакаева 2003: 88]. В калмыцком языке значения слова савр 'когти; лапа; конечности’ [КРС 1977: 435]. В монгольском языке лексема савар имеет следующие значения: '1) когти (у зверей и птиц); бүргэдийн савар орлиные когти; харцагын 
савар ястребиные когти; савар зуурах сжимать когти; 2) лапа; баавгайн савар медвежья лапа (с когтями); савар нээх открыть лапу; распустить когти; 3) үл. тааш. руки; гар савар / хөл савар хорш. а) лапы; б) шилж. руки, ноги; савраа mam! руки прочь!; шаазгайн савар ург. крестики; савар элсэг амьт. песочник длиннопалый’ [БАМРС 2001: 65].

Н. Б. Дашиева, ссылаясь на значения, приводимые Э. П. Бакаевой, этимологизирует это имя от названия шаманской колотушки, изготавливаемой из медвежьей лапы [Дашиева 2001: 166]. Ученый предполагает, что, возможно, образ Савара восходит к более древнему пласту и связан с образом медведя, который в раннем мифе преследует в течение ночи лосиху с теленком, которые затем превращаются в созвездия Арктур, Большой Медведицы и Малой Медведицы [Дашиева 2001: 94].

Отметим, что у закаменских бурят одним из табуированных названий медведя было «Анда-Бараа ан», восходящее к воззрениям о медведе как сородиче матери - дяди со стороны матери [Дашиева 2001: 141-142]. А в калмыцком эпосе только богатырь Савар считается пришлым, с которым приходится совершить обряд побратимства анда болх.

Таким образом, мотив охоты богатыря Савара на оленей и маралух, на наш взгляд, находится в одном семантическом поле с сюжетом о медведе, преследующем олениху, укравшую солнце. Это подтверждает мнение Э. П. Бакаевой о том, что «...у этнических предков калмыков в прошлом существовал древний сезонный календарь, в котором маркерами двух основных сезонов являлись образы медведя и оленя, связанные с периодами зимы и лета» [Бакаева 2020б: 668].

\section{«Огненное, солнечное начало» трех маралух}

Как и фигура охотника, так и персонажи маралы/олени в калмыцком фольклоре - это образы, вобравшие разностадиальные представления и знания народа.

Н. Б. Дашиева констатирует, что «...смена основного мифологического кода календаря, присущего культуре охотников, у скотоводческих народов коррелировала со сменой мировоззренческих аспектов, связанных с представлениями об истоках жизни и смерти. Если в архаичных мифах творения копытные выступают в роли хтонических противников Солния, то новые идеи отводят небесным маралам роль матерей-прародительнии, источника рождения Солнца» [Дашиева 2001: 180]'.

По всей видимости, такая смена отражена и в эпическом тексте раннего Багацохуровского цикла, который свидетельствует о двух важных функциях оленухи как хранительницы внешней души и матери-прародительницы в образе копытного, последнее проявляется в имплицитном виде через семантическую природу:

III песнь Б. Ц. — [39] (4) naran yaraxuin ömnö züq dēdü debēn gedeq ūla baiduq bolnai: (9) tere ūlān orō dēreni altan bindaraya önggö- (10) tei arban sayixan zandan modun kürēlen uruүuqsan: moduni dotoroni yurban önggö cecegēr (11) küreleqseni dotoroni šara ulān kökö yurban altan maral: dunduki maraliyin dotoroni yurban (12)

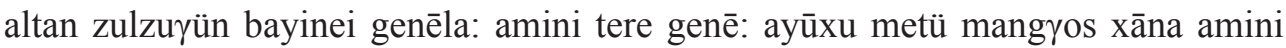
biyedüni (13) ügei 'В стороне восходящего солнца находится гора Деде Девян.

\footnotetext{
${ }^{9}$ Курсив автора.
} 
На вершине той горы цвета золота и бирюзы десять прекрасных сандалов, круг образуя, выросли. В том круге деревьев круг из цветов, излучающих три цвета. Внутри желтый, красный, синий, три золотые маралухи [находятся]. Во чреве средней маралухи три золотых детеныша есть, говорят. Они - душа [мангаса], говорят. У грозного Мангас-хана в теле нет души, говорят' [РО БВФ СПбГУ. Calm. С. 17. Л. 39].

Н. Б. Дашиева замечает, что «...в ранних представлениях тюрко-монгольских народов мать-прародительница в образе копытного обладала не только функциями рождения Солнца, но и выступала в качестве источника наделения душой людей» [Дашиева 2001: 182].

Представление о бессмертии эпического героя, в частности мангаса, генетически восходит к образу «внешней» души, так как у калмыков бытовали традиционные представления о разных душах [Бакаева 2003: 157].

Если текст напрямую свидетельствует о трех золотых маралухах как хранительницах души, то о возможной функции матери-прародительницы свидетельствуют косвенно элементы данного эпизода.

Во-первых, это образы маралов/оленей, являющихся символами Солнца. Это золотой цвет детенышей в чреве маралухи, свидетельствующий об их солнечной природе. Так, «цвета золота и бирюзы» и деревья, растущие кругом и излучающие цвета; вероятно, это связано с символическим изображением солярно-лунарного круга. Как пишет Г. Р. Галданова, у бурят «...солнце изображается в виде восьми кругов, с отходящими от внешнего круга лучами - восьмилучевое солнце; луна — в виде девяти кругов, без лучей» [Галданова 1987: 20]. Деревья числом десять, возможно, символизируют десять стрел, которые Н. Б. Дашиева интерпретирует как «числовой код сидерических месяцев, совпадающих по длительности со сроком вынашивания плода...» [Дашиева 2001: 199], что соответствует идее «творение-рождение».

\section{Заключение}

Эпический сюжет о двигающемся по лунной дороге богатыре Саваре, охотящемся на оленей и маралов, на наш взгляд, восходит к космогоническому мифу о небесном стрелке (=Сириус) и копытных (= звезды из пояса созвездия Орион). Более того, образ богатыря Савара, возможно, восходит к архаическому мифу о медведе-охотнике, преследующем оленей, укравших солнце. Такая интерпретация архаического сюжета из раннего Багацохуровского цикла калмыцкого героического цикла «Джангар» подтверждает мнение Э. П. Бакаевой о том, что в архаичном календаре калмыков «основными символами являлись образы копытного животного и медведя» [Бакаева 2010: 299] и концепцию Н. Б. Дашиевой о том, что образ небесного стрелка сменил мифологический облик медведя, освобождающего солнце в древнейшем мифе о первотворении [Дашиева 2001: 167]. К тому же семантика образов соответствует календарной традиции, зафиксированной в XIX в. и, вероятно, бывшей характерной для более раннего времени.

Несмотря на отсутствие среди калмыков мифологических сказаний на данную тему, эпический текст хранит архетипические значения общего знания традиции. 


\section{Источники}

НА РГО. Оп. 1. Р. 53. Д. 15 - Научный архив Русского Географического общества. Оп. 1. Разряд 53. Д. 15. Л. 1-30об. Рукопись на ойратской письменности.

РО БВФ СПбГУ. Calm. C. 17 - Рукописный отдел Библиотеки Восточного факультета Санкт-Петербургского государственного университета. Calm. C. 17. Ед. хр. 1770. Л. 1-28. Строки 30-31. Рукопись на ойратской письменности.

\section{Sources}

Russian Geographical Society, Scientific Archive. Manuscript. Cat. 1. Series 53. File 15. P. 1-30. (In Oir.)

St. Petersburg State University, Faculty of Asian and African Studies, Manuscript Department. Manuscript. Calm. C. 17. File no. 1770. P. 1-28. Lines 30-31. (In Oir.)

\section{Литература}

Бакаева 2003 - Бакаева Э. П. Добуддийские верования калмыков. Элиста: АПП «Джангар», 2003. 358 c.

Бакаева 2009 - Бакаева Э. П. Сакральные коды культуры калмыков. Элиста: ИКИАТ, 2009. $159 \mathrm{c}$

Бакаева 2010 - Бакаева Э. П. Календарная обрядность // Калмыки / отв. ред. Э. П. Бакаева, Н. Л. Жуковская. М.: Наука, 2010. С. 290-300.

Бакаева 2020а - Бакаева Э. П. Почитание Большой Медведицы в среде ойратов и калмыков: древнейшие представления и буддийские напластования. Часть $1 / /$ Oriental Studies. 2020. T. 13. № 2. C. 368-384. DOI: 10.22162/2619-0990-2020-48-2-368-384

Бакаева 2020б - Бакаева Э. П. Почитание Большой Медведицы в среде ойратов и калмыков: древнейшие представления и буддийские напластования. Часть 2 // Oriental Studies. 2020. T. 13. № 3. С. 661-687. DOI: 10.22162/2619-0990-2020-49-3-661-687

БАМРС 2001 - Большой академический монгольско-русский словарь / отв. ред. Г. Ц. Пюрбеев. В 4-х тт. Т. 3. Ө-Ф. М.: Academia, 2004. 440 с.

Галданова 1987 - Галданова Г. Р. Доламаистские верования бурят. Новосибирск: Наука, 1987. 113 с.

Данилова 2016 - Данилова Н. К. Сакральное пространство: архитектурное воплощение традиционного мировоззрения народа саха // Вестник Томского государственного университета. История. 2016. № 1 (39). С. 135-142.

Дашиева 2001 - Дашиева Н. Б. Календарь в традиционной культуре бурят (опыт историко-этнографического и культурно-генетического исследования). Улан-Удэ: Издательско-полиграфический комплекс ВСГАКИ, 2001. 299 с.

Дашиева 2004 - Дашиева Н. Б. Лунно-солнечный календарь по созвездиям Ориона и Сириуса // Буряты / отв. ред. Л. Л. Абаева, Н. Л. Жуковская. М.: Наука, 2004. C. $225-226$.

Кичиков 1980 - Кичиков А. Ш. Об итогах изучения «Джангара» // «Джангар» и проблемы эпического творчества тюрко-монгольских народов: мат-лы Всесоюзн. науч. конф. (г. Элиста, 17-19 мая 1978 г.). М.: Наука, ГРВЛ, 1980. С. 428-436.

КРС 1977 - Калмыцко-русский словарь. М.: Рус. яз., 1977. 768 с.

Лепехин 1771 - Лелехин И. И. Дневные записки путешествия доктора и Академии наук адъюнкта Ивана Лепехина по разным провинциям Российского государства в 1768-1769 году. Ч. 1. СПб.: При Императорской Академии наук, 1771. 537 с.

Омакаева 1993 - Омакаева Э. У. Культ небесных светил у калмыков // І Международная конференция «Традиционные культуры и среда обитания». М.: Наука, 1993. C. $150-153$.

Паллас 1773 - Паллас П. С. Путешествие по разным провинциям Российской империи. Ч. 1. СПб.: При Императорской Академии наук, 1773. 117 с.

Попов 1919 - Попов И. И. Донские калмыки-казаки // Очерки географии Всевеликого войска Донского / сост. В. Б. Богачев. Новочеркасск: Отдел народного просвещения Всевеликого Войска Донского, 1919. 523 с. 
Пюрбеев 2015 - Пюрбеев Г. Ц. Эпос «Джангар»: культура и язык (= Жаңһр дуулвр: сойл болн келн) / на рус. и калм. яз. 2-е изд., перераб. Элиста: НПП «Джангар», 2015. $280 \mathrm{c}$.

Романова 2012 - Романова Е. Н. Календарь // Якуты Саха / отв. ред.: Н. А. Алексеев, Е. Н. Романова, 3. П. Соколова. М.: Наука, 2012. 598 с.

Тодаева 2001 - Тодаева Б. Х. Словарь языка ойратов Синьцзяна (По версиям песен «Джангара» и полевым записям автора). Элиста: Калм. кн. изд-во, 2001. 494 с.

\section{References}

Bakaeva E. P. Calendar of rites. In: Bakaeva E. P., Zhukovskaya N. L. (eds.) The Kalmyks. Moscow: Nauka, 2010. Pp. 290-300. (In Russ.)

Bakaeva E. P. Pre-Buddhist Beliefs of Kalmyks. Elista: Dzhangar, 2003. 358 p. (In Russ.)

Bakaeva E. P. Sacral Codes of Kalmyk Culture. Elista: IKIAT, 2009. 159 p. (In Russ.)

Bakaeva E. P. Veneration of Ursa Major among the Oirats and Kalmyks: Ancient beliefs and later Buddhist additions. Part 1. Oriental Studies. 2020. Vol. 13. No. 2. Pp. 368-384. (In Russ.) DOI: 10.22162/2619-0990-2020-48-2-368-384

Bakaeva E. P. Veneration of Ursa Major among the Oirats and Kalmyks: Ancient beliefs and later Buddhist additions. Part 2. Oriental Studies. 2020. Vol. 13. No. 3. Pp. 661-687. (In Russ.) DOI: 10.22162/2619-0990-2020-49-3-661-687

Danilova N. K. Sacral space: Architectural embodiment of traditional outlook. Tomsk State University Journal of History. 2016. No. 1 (39). Pp. 135-142. (In Russ.)

Dashieva N. B. Calendar in Buryat Traditional Culture: A Study in History, Ethnography, and Cultural Genetics. Ulan-Ude: East Siberian State Academy of Culture and Arts, 2001. 299 p. (In Russ.)

Dashieva N. B. Moon and solar calendar by Orion and Sirius constellations. In: Abaeva L. L., Zhukovskaya N. L. The Buryats. Moscow: Nauka, 2004. Pp. 225-226. (In Russ.)

Galdanova G. R. Pre-Lamaist Beliefs of Buryats. Novosibirsk: Nauka, 1987. 113 p. (In Russ.)

Kichikov A. Sh. Epic of Jangar: research outcomes. In: Jangar and Issues of Turko-Mongolian Epic. Conference proceedings (Elista; May 17-19, 1978). Moscow: Nauka — GRVL, 1980. Pp. 428-436. (In Russ.)

Lepekhin I. I. Across Different Provinces of Russia, 1768-1769: Daily Travel Notes by Ivan Lepekhin, Medical Doctor and Adjunct Professor. Part 1. St. Petersburg: Imperial Academy of Sciences, 1771. 537 p. (In Russ.)

Muniev B. D. (ed.) Kalmyk-Russian Dictionary. Moscow: Russkiy Yazyk, 1977. 768 p. (In Kalm. and Russ.)

Omakaeva E. U. Kalmyk cult of celestial bodies. In: Traditional Cultures and Environment. Conference proceedings. Moscow: Nauka, 1993. Pp. 150-153. (In Russ.)

Pallas P. S. A Journey across Different Provinces of the Russian Empire. Part 1. St. Petersburg: Imperial Academy of Sciences, 1773. 117 p. (In Russ.)

Popov I. I. Kalmyk Don Cossacks. In: Bogachev V. B. (comp.) Almighty Don Host: Geographical Essays. Novocherkassk: Public Education Department (Almighty Don Host), 1919. 523 p. (In Russ.)

Pyurbeev G. Ts. (ed.) Unabridged Academic Mongolian-Russian Dictionary. In 4 vols. Vol. 3 : Ө-Ф. Moscow: Academia, 2004. 440 p. (In Mong. and Russ.)

Pyurbeev G. Ts. Epic of Jangar: Culture and Language. $2^{\text {nd }}$ ed., rev. Elista: Dzhangar, 2015. 280 p. (In Kalm. and Russ.)

Romanova E. N. Calendar. In: Alekseev N. A., Romanova E. N., Sokolova Z. P. (eds.) The Yakuts. The Sakha. Moscow: Nauka, 2012. 598 p. (In Russ.)

Todaeva B. Kh. Dictionary of Xinjiang Oirat. Elista: Kalmykia Book Publ., 2001. 494 p. (In Kalm. and Russ.) 